\title{
(2) OPEN ACCESS \\ Drive-through testing for SARS-CoV-2 in symptomatic health and social care workers and household members: an observational cohort study
}

\author{
Benjamin J Parcell, ${ }_{1}^{1}$ Kathryn Brechin, ${ }^{2}$ Sarah Allstaff, ${ }^{3}$ Meg Park, ${ }^{4}$ Wendy Third, ${ }^{5}$ \\ Susan Bean ${ }_{1}^{4}$ Chris Hind, ${ }^{1}$ Rajiv Farmer, ${ }^{6}$ Daniel Chandler, ${ }^{7}$ James D Chalmers ${ }^{8}$
}

${ }^{1}$ Department of Medical Microbiology, Ninewells Hospital and Medical School Dundee, UK

${ }^{2}$ Ninewells Hospital and Medical School, Dundee, UK

${ }^{3}$ Tayside Sexual and Reproductive Health Service, Ninewells Hospital and Medical School, Dundee, UK

${ }^{4}$ Department of Medicine and Cardiovascular, Ninewells Hospital and Medical School, Dundee, UK

${ }^{5}$ Dundee Health and Social Care Partnership, Dundee, UK ${ }^{6}$ Virology Department, Ninewells Hospital and Medical School Dundee, UK

${ }^{7}$ NHS Tayside, Dundee, UK ${ }^{8}$ Division of Molecular and Clinical Medicine, University of Dundee, Dundee, UK

\section{Correspondence to}

Dr Benjamin J Parcell, Medical Microbiology, Dundee DD1 9SY, UK; BJParcell@dundee.ac.uk

Received 24 April 2020 Revised 28 July 2020 Accepted 28 July 2020 Published Online First 27 August 2020
Check for updates

(C) Author(s) (or their employer(s)) 2020. Re-use permitted under CC BY-NC. No commercial re-use. See rights and permissions. Published by BMJ.

To cite: Parcell BJ, Brechin K, Allstaff $S$, et al. Thorax 2020;75:1109-1111.

\section{ABSTRACT}

The requirement for health and social care workers to self-isolate when they or their household contacts develop symptoms consistent with severe acute respiratory syndrome coronavirus 2 (SARS-CoV-2) infection can lead to critical staff shortages in the context of a pandemic. In this report, we describe the implementation of a drive-through testing service in a single National Health Service region in Scotland. From 17 March 2020 to 11 April 2020, 1890 SARS-CoV-2 reverse transcription $P C R$ assay (RT-PCR) tests were performed. $22 \%$ of tests were positive. Allowing the remaining $78 \%$ of staff to return to work within 24 hours was estimated to save over 8000 working days during the peak pandemic period.

Health and social care workers (HSCWs) are disproportionately infected with severe acute respiratory syndrome coronavirus 2 (SARS-CoV-2). Healthcare workers accounted for $21 \%$ of cases of SARS during the 2002 outbreak, ${ }^{1}$ and recent experience in China and Italy confirms high rates of healthcare worker infections during the current pandemic. ${ }^{2} 3$ In addition to the direct effects of the virus on HSCWs, infections have indirect effects on their families and staff morale and can have a significant impact on the ability of healthcare systems to function due to staff absence. Current UK guidance requires that HSCWs experiencing symptoms should be absent from work for 7 days, while if they live with a symptomatic household contact (SHC), the staff member should be absent from work for 14 days to account for the incubation period of the virus. Rapid availability of testing to exclude SARS-CoV-2 infection would allow critical healthcare staff to return to work.

In this letter, we describe the results of a testing programme for symptomatic HSCWs and SHCs in a single UK region (Tayside, Scotland). The testing service was established on 17 March 2020 as the first in the country and was initiated by local clinicians and National Health Service (NHS) Tayside management. Samples were collected at a drivethrough testing hub at a local community hospital with the testing site selected as it was remote from the main university teaching hospital and provided adequate vehicle access, parking and testing facilities. $^{45}$ At the time of writing, the facility employs 55 staff. The site was available to any staff within the Tayside region. While the majority of staff are resident in Dundee, some staff from the wider region would have had to travel 20-30 miles to access the site. The definition of HSCWs included all key workers such as doctors, nurses, pharmacists, porters, healthcare assistants, paramedics and social care staff particularly those working in care homes or in the community. The testing model can be seen in figure 1 . Combined nasal-pharyngeal swabs were taken for reverse transcription PCR assay (RT-PCR) as previously described. ${ }^{6}$ HSCWs were able to return to work following a negative test with results available within 24 hours. Days of staff absence potentially saved were therefore calculated as the average number of working days following a negative test (up to a maximum of 6 days for staff members and 13 days in the case of SHCs). A worst-case scenario in which testing only saved 3 days and 10 days was also calculated (in this scenario a HSCW developing symptoms during a weekend would self-isolate for 3 days before they could receive testing and a further day while awaiting the results of the test). ${ }^{7}$

From 17 March 2020 to 11 April 2020, 1890 tests were performed by the service. ${ }^{3}$ Some individuals were tested more than once and therefore 1887 individuals were tested. In 1173 cases (62.1\%), the HSCW themselves were tested; in 374 cases $(19.8 \%)$, an adult SHC was tested. In 155 cases, a child SHC was tested (8.2\%). In 188 cases $(9.9 \%)$, it could not be determined whether an HSCW or SHC was tested. A total of 325 out of $1173(27.7 \%)$ HSCWs, $73 / 374$ (19.5\%) adult contacts and 4/155 (2.6\%) child contacts tested positive for SARS-CoV-2. Fifteen of 188 undetermined cases were positive $(8.0 \%)$. Clinical information was available for 1727 HSCWs and SHCs. The most frequently reported symptom was cough with 1369/1727 (79.3\%) followed by fever with 619 (35.8\%), sore throat with 294 (17.0\%) and shortness of breath with 97 (5.6\%). Anosmia was not part of the original case definition and was not collected. Data on ethnicity were not collected, but data from 2019 showed that the NHS Tayside workforce was $97 \%$ white. Based on the reported isolation time in each case and a typical 40 hours working week, we estimate that testing therefore prevented up to 3634 lost work days from HSCW testing, 2795 from adult SHC testing and 1402 lost work days from child SHC testing.

Assuming a worst-case scenario in which all 188 undetermined cases were HSCWs, rather than SHCs, this equates to 8573 lost working days prevented through testing. Under the more conservative 


\section{NHS Tayside Staff Testing - COVID-19}

Figure 1 Process for requesting testing and reporting results. This illustrates the requirements for a successful testing programme including: (1) clear criteria for referral for testing; (2) sufficient adequately trained staff to perform testing; (3) a suitable location to set-up a drive through testing hub; (4) a robust process for managing and reporting back results to staff members; (5) sufficient testing capacity to process staff RT-PCR tests; and (6) ability to adapt the service to changing epidemiology, staff needs and case definitions in the context of an outbreak. CTT, community testing team.

scenario where the majority of symptoms developed at weekends or staff had a longer delay to obtain testing, the saving was estimated at 6679 days. At the time of writing, there were no cases in which negative HSCWs subsequently tested positive for the disease. No healthcare-associated outbreaks linked to staff that had been previously tested were reported during the study period.

To our knowledge, this is the first report of a systematic testing programme for HSCWs and SHCs across a healthcare region designed to ensure healthcare system resilience by reducing sickness absence. The results show a striking saving of over 8000 lost working days for health and social care staff over a period of just 3 weeks, which is likely to have had a significant impact on the ability of health systems to respond to the SARS-CoV-2 pandemic. Inclusion of SHCs in the testing programme accounted for more than $50 \%$ of the estimated work days saved is a key difference between this programme and others that have reported in the UK. ${ }^{8}$ The risk of SARS-CoV-2 infection can have an important effect on mental health and rapid access to testing may be an important part of mitigating these effects. ${ }^{9}$ There are some important considerations when implementing a staff testing programme. First, nasopharyngeal and oropharyngeal swabs have been reported to have a sensitivity ranging from
$63 \%$ to $90 \% .{ }^{1011}$ It is therefore theoretically possible that some individuals tested in our study returned to work with a 'falsenegative' result. We acknowledge this is a risk, but this small risk must be balanced against the risk of decimating the healthcare workforce during a pandemic. It is acknowledged that the precise number of working days saved through this practice is difficult to estimate as not all HCSWs would be working full time and on all days during the isolation periods and may not always be tested on the first day of symptoms that leads us to overestimate days saved. Therefore, the estimates provided should be treated with caution but likely represent the maximum utility of a healthcare working testing programme. Future studies evaluating testing programmes such as this should consider incorporating a simple questionnaire including information about full-time versus part-time work and number of HSCWs in the household to allow more accurate estimates in future. The ability to perform over 1800 RT-PCR tests for SARS-CoV-2 is only possible if there is sufficient testing capacity. A prioritisation process for SARS-CoV-2 testing was implemented in the region during this period with five levels of testing: (1) patients with suspected COVID-19 infection with clinical need for testing; (2) symptomatic HSCWs or SHCs; (3) asymptomatic HSCWs or patients-residents in the context of an outbreak; (4) sampling 
for admissions and transfers between acute, social care and community settings; and (5) other screening such as surveillance in inpatients over the age of 70 years. Testing capacity was not exceeded, and therefore rationing of testing was not required. A limitation to the drive through testing model is that it requires access to a vehicle and may therefore exclude some staff. Alternative testing models are needed to enable access for all staff.

Maintaining adequate staffing of the social care sector, wards, intensive care units and primary care assessment units is important during a pandemic, and we demonstrate that screening of healthcare workers and SHCs can markedly reduce the number of staff work days lost due to self-isolation.

Acknowledgements The authors acknowledge the contribution of the staff at the National Health Service Tayside COVID-19 testing facility, the Infection, Prevention and Control Team and the virology laboratory at Ninewells Hospital, Dundee. This study was published initially as a preprint.

Contributors Study design: BJP, KB, SA and JDC. Data acquisition: all authors. Data analysis: BJP, SA and JDC. Wrote first draft: JDC. Revision of the paper and approval of the final version: all authors.

Funding JDC is supported by the GSK/British Lung Foundation Chair of Respiratory Research and a Senior Fellowship from the Chief Scientist Office, Scotland.

Competing interests JDC declares fees for consultancy and research grants from Astrazeneca, Boehringer Ingelheim, Chiesi, Glaxosmithkline, Gilead Sciences, Insmed and Zambon outside the submitted work.

Patient consent for publication Not required.

Provenance and peer review Not commissioned; externally peer reviewed.

Open access This is an open access article distributed in accordance with the Creative Commons Attribution Non Commercial (CC BY-NC 4.0) license, which permits others to distribute, remix, adapt, build upon this work non-commercially, and license their derivative works on different terms, provided the original work is properly cited, appropriate credit is given, any changes made indicated, and the use is non-commercial. See: http://creativecommons.org/licenses/by-nc/4.0/.

\section{REFERENCES}

1 Parcell B, Brechin K, Allstaff S, et al. Drive-through testing for SARS-CoV-2 in symptomatic health and social care workers and household members: an observational cohort study in Tayside, Scotland. medRxiv.

2 World Health Organization. Case definitions for surveillance of severe acute respiratory syndrome (SARS), 2003. Available: (https://www.who.int/csr/sars/ casedefinition/en/) [Accessed 13 Apr 2020].

3 World Health Organisation. Report of the WHO-China joint mission on coronavirus disease 2019 (COVID-19), 2020. Available: https: // ttps://www.who.int/docs/defaultsource/coronaviruse/who-china-joint-mission-on-covid-19-final-report.pdf. [Accessed 13 Apr 2020].

4 Remuzzi A, Remuzzi G. COVID-19 and Italy: what next? Lancet 2020;395:1225-8.

5 Kwon KT, Ko JH, Shin H, et al. Drive-through screening center for COVID-19: a safe and efficient screening system against massive community outbreak. J Korean Med Sc 2020;35:e123.

6 Ton AN, Jethwa T, Waters K, et al. COVID-19 drive through testing: an effective strategy for conserving personal protective equipment. Am J Infect Control 2020;48:731-2.

7 NHS England. Guidance and standard operating procedure. Available: https://www. england.nhs.uk/coronavirus/wp-content/uploads/sites/52/2020/03/guidance-and-sopcovid-19-virus-testing-in-nhs-laboratories-v1.pdf

8 Keeley AJ, Evans C, Colton $\mathrm{H}$, et al. Roll-out of SARS-CoV-2 testing for healthcare workers at a large NHS Foundation trust in the United Kingdom, March 2020. Euro Surveill 2020:25:2000433.

9 Xiang Y-T, Yang Y, Li W, et al. Timely mental health care for the 2019 novel coronavirus outbreak is urgently needed. Lancet Psychiatry 2020;7:228-9.

10 Loeffelholz MJ, Tang Y-W. Laboratory diagnosis of emerging human coronavirus infections - the state of the art. Emerg Microbes Infect 2020:9:747-56.

11 Wang W, Xu Y, Gao R, et al. Detection of SARS-CoV-2 in different types of clinical specimens. JAMA 2020;323:1843-4. 